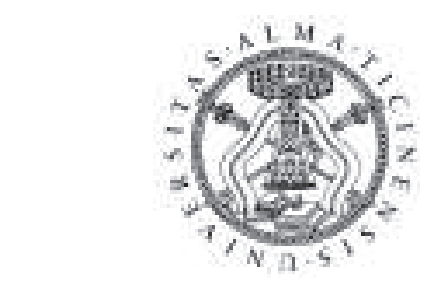

UNIVERSITÀ DEGLI STUDI

DI PAVIA

DIPARTIMENTO DI BIOCHIMICA

"A. Castellani"

\title{
Proceedings
}

\section{Meeting \\ THE ITALIAN SOCIETY \\ FOR THE STUDY OF CONNECTIVE TISSUES (SISC)}

September 22-23, 2005

Pavia

Dipartimento di Biochimica "A. Castellani"

Editors

M. Enrica Tira and Ruggero Tenni 


\title{
Local Organization
}

Cesare Balduini

Giuseppe Cetta

Antonella Forlino

Antonio Rossi

M. Enrica Tira

Ruggero Tenni

\author{
Supported by \\ Università degli Studi di Pavia \\ Dipartimento di Biochimica "A. Castellani" \\ Our thanks for technical support to \\ Marilena Nascimbene \\ Vera Sarchi
}




\section{LECTURE IN HONOUR OF ALESSANDRO A. CASTELLANI}

\section{Human sialidases: molecular biology, biochemistry and physiopathological implications}

G. Tettamanti

Department of Medical Chemistry, Biochemistry and Biotechnology, The Medical School, University of Milan, Segrate, Milan, Italy

Sialidases are expressed in viruses, bacteria, protozoa and vertebrates. Viral, bacterial and protozoan sialidases display about 35\% homology in their primary structure, and share some specific motifs: six four-stranded antiparallel $\beta$-sheets arranged as the blades of a propeller; a F(Y)RIP motif located toward the aminoterminal region; a repetitive motif SXDXGXXT/W in the active site region; some Asp-boxes. In mammalian (including human) organs and tissues, sialidases display different subcellular locations (lysosomes, plasma membrane, cytosol and, possibly, other locations) and substrate specificities. The lysosomal, cytosolic and plasma membrane sialidases, also from the same animal, have different protein structure, antigenic properties and cDNAs.

So far, the following human sialidases have been cloned: the lysosomal sialidase NEUI coded by NEUI gene mapped in 6p21, the cytosoluble sialidase NEU2 coded by NEU2 gene mapped in 2q37, the plasma membrane bound sialidase NEU3 coded by NEU3 gene mapped in 11q13, and the sialidase NEU4 coded by NEU4 gene mapped in 2937 . The corresponding recombinant sialidases constitute powerful tools for studying the structure-function relationships of these enzymes. As an example, recombinant human cytosolic sialidase ( $\mathrm{Hs}$ $N E U 2)$, expressed in E. Coli, was purified to homogeneity and its crystal structure defined. The presence of the canonical six blades $\beta$-propeller structure, F (Y)RIP motifs and three Aspboxes, typical of all studied sialidases, was confirmed. In addition, with the use of the inhibitor DANA (2,3-dehydro3-deoxy-N-acetylneuraminic acid) the dynamic nature of substrate recognition was assessed. Recombinant Hs NEU2 was proven to differentially recognise: (a) the type of sialosyl linkage; (b) the aglycone part of the substrate (gangliosides act as the best substrates); and (c) the supra-molecular organization (monomer, micelle, vesicle) of the ganglioside substrate. The latter ability might be relevant in sialidase interactions with gangliosides under physiological conditions.

Some plasma membrane bound sialidases appear to be attached to the membrane via a glycan-phosphoinositide (GPI) anchor, possibly indicating their location in specialized plasma membrane "domains" (lipid rafts). Surface sialidase NEU3 is able to affect sialoglycolipids exposed on the surface of vicinal cells and was shown to be directly involved in neural (with a specific location on the "growth cones") and myoblast differentiation. In the latter case the block of sialidase expression led to inhibition of the differentiation toward myocytes. Sialidases appear also to be involved in human erythrocytes maturation and ageing under physiological and pathological conditions. Very recent results point to the implication of sialidase NEU3, and its hydrolysis products gangliosides $\mathrm{GMI}$ and $\mathrm{GM} 2$, in the insulin post-receptor signaling events, and of sialidases NEU2 and NEU 3 in tumor growth. The genetic lack of sialidase NEUI is responsible of a very severe lysosomal disease.

\section{LECTURE IN HONOUR OF LORENZO GOTTE}

The supramolecular organization of elastin in the elastic fiber scaffold of heart valves

M. Spina, F. Naso, M. Marchini, ${ }^{1}$ F. Ortolani, ${ }^{1}$ A. Gandaglia

Department of Experimental Biomedical Sciences, University of Padova; 'Department of Medical and Morphological Research, University of Udine; Italy

Elastin is a highly cross-linked polymer that confers elasticity to soft connective tissues in vertebrates. It forms huge branched fibers and lamellae of the order of 0.1 to 10 micron thick and several microns long, according to different organs. The monomeric unit is approximately a $60-k \mathrm{Da}$ protein but still the mechanism and the steps by which the monomer aggregates to give rise to the supramolecular architecture in the tissue is substantially not understood.

The elastic scaffold of pig heart valve was isolated by means of non-degradative procedure and analysed by TEM as well as by OM, SEM and ESEM in controlled conditions in order to evaluate possible distorsion and modification of the tridimensional architecture induced by the observation procedures. Eventually the elastic scaffold was fragmented by ultrasonication at different temperature and the resulting fragments observed by SEM and ESEM.

Fiber, lamellar aggregates and thin sheets composed the typology of the morphological elements. Thicker fibers and lamellae apparently resulted from longitudinal and planar net aggregation of thinner fibrillar elements of the order of $100-$ $140 \mathrm{~nm}$ exhibiting an elliptical cross-section. However the shape of thicker fibers was not constant and the diameter did not to result simply from the addition of smaller discrete elements, branching was frequent and at different angle. The shape of thicker fibers was cylindrical, flat ribbon- and twisted ribbon-like. Very thin sheets were spread between fibers and lamellae and often did roll over becoming integral part of the surrounding fibrous elements. After ultrasonication thicker fibers did not resolve into thinner fibrillar elements but in sheets and cylindrical flakes.

The whole of the experimental evidence does not indicate the presence of a subfibrillar architecture. Apparently fibers may result from the aggregation of laminar components. 


\section{CONNECTIVE TISSUES: MORPHOLOGY, MOLECULES AND CELLS}

\author{
Overexpression of $\alpha 5$ integrin and its role in muscle \\ development \\ B. Bartolini, ${ }^{1}$ L. Rogers, ${ }^{2}$ S. Wild, ${ }^{2}$ U. Mayer ${ }^{2}$ \\ ${ }^{1}$ Dipartimento di Biochimica, Università degli Studi di Pavia, \\ Pavia, Italy; ' Wellcome Trust Centre for Cell-Matrix \\ Research, Smith Building, University of Manchester, \\ Manchester, UK
}

Integrins are molecules that transmit signals bidirectionally across the plasma membrane. In mammalian skeletal muscle, the $\beta 1$ family of integrins is found at neuromuscular junction (NMJ), myotendinous junction (MTJ) and the sarcolemma, though their expression vary depending on the stage of development. $\alpha 5 \beta 1$ and $\alpha 7 \beta 1$ are among the major players in muscle differentiation: during embrionic stage $\alpha 5 \beta 1$ is found at the MTJ and is substituted by $\alpha 7 \beta 1$ in the adult. Both of the subunits have been involved in the development of muscular dystrophy. To understand the crosstalk between $\alpha 5$ and $\alpha 7$, mice overexpressing $\alpha 5$ have been generated: the overexpression was controlled by the human skeletal $\alpha$-actin promoter whose onset expression is at embryonic day 12 or by the muscle creatine kinase promoter whose onset expression is at birth. Sub-strains overexpressing a mutated form of the $\alpha 5$ subunit have been generated as well. Immunoprecipitation and immunoblotting were used to investigate the formation of $\alpha 5 \beta 1$. The co-localization of the subunits was checked by immunostaining of muscles. In the overexpressors, $\alpha 5$ associated with $\beta 1$, with the exception of the mutant. Immunostaining showed a decrease of the two $\alpha 7$ splice variants especially at the MTJ, substituted by an increase of $\alpha 5$. All the mice showed muscular dystrophy. It seems that the two $\alpha$ subunits were competing for association with $\beta 1$, as in the integrin $\alpha 7$ knock out muscle $\alpha 5$ is the only $\alpha$ subunit to co-precipitate with $\beta 1$. This analysis suggests the roles of $\alpha 5$ and $\alpha 7$ in muscle development and integrity and that the correct conformation of integrin $\alpha 5$ is vital to muscle fibre integrity.

\section{The role of the hypoxic condition on the protein profile of human fibroblasts}

F. Boraldi, G. Annovi, F. Carraro, ${ }^{1}$ I. Pasquali Ronchetti, R. Tiozzo, D. Quaglino

Department of Biomedical Sciences, University of Modena and Reggio Emilia, Modena; 'Department of Physiology, University of Siena, Siena, Italy

Tumor progression is influenced by extracellular matrices and by soluble factors or cytokines that are locally produced by host tissue cells and that may sustain one of the most insidious aspect of tumors, namely their propensity to invade normal tissues and to form metastases in organs at distant sites from the primary tumor. It is generally accepted that growth of solid tumors is dependent on the formation of new blood vessels. The angiogenic response of the host is mediated by angiogenic molecules that are released from cancer and normal stroma cells, especially fibroblasts. Moreover, under hypoxic conditions such as those found during tumor growth, a variety of angiogenic growth factors are upregulated in normal and transformed cells, suggesting that an interrelationship between hypoxia and angiogenesis may exist. Most studies on oxygen-dependent regulation of gene expression have been performed with tumor cells; however, besides tumor cells, normal stroma cells, eg, endothelial cell, immune competent cells and fibroblasts, may change their protein profile and phenotype, thus influencing neighbouring cells. Human dermal fibroblasts were grown for
$96 \mathrm{~h}$ in $5 \% \quad \mathrm{CO}_{2}$ and $21 \% \mathrm{O}_{2} \quad\left(\mathrm{pO}_{2}=140 \mathrm{mmHg}\right)$ or $2 \% \quad \mathrm{O}_{2}$ $\left(\mathrm{pO}_{2}=14 \mathrm{mmHg}\right)$. The hypoxic condition does not influence the proliferation rate as well as the protein content of fibroblasts. By proteome analysis we demonstrated that 27 protein were differentially expressed at least three times in the two experimental conditions, in particular 30\% appeared upregulated whereas $70 \%$ were downregulated in the hypoxic conditions. By mass spectrometry we identified elongation factor $1-\alpha 1, \alpha-$ enolase, protein disulfide isomerase, pyruvate kinase, NDRG1 protein, $40 S$ ribosomal protein $S A$, calmodulin, fetuin-A and parathymosin among the proteins whose expression was influences by changes in the $\mathrm{pO}_{2}$. In conclusion, data indicate that fibroblast respond to the hypoxic condition by activating stress response pathways and possibly altering post-translational protein maturation.

Financial support from MIUR (2004059221).

\section{Cytokines-induced increase of cell hyaluronan synthase activity: studies after oxidative injury in fibroblast cultures}

G.M. Campo, A. D'Ascola, S. Campo, A. Avenoso, A.M. Ferlazzo, ${ }^{1}$ A. Calatroni

Department of Biochemical, Physiological and Nutritional Sciences, 'Department of Morphology, Biochemistry, Physiology and Animal Production, University of Messina, Italy

It was previously reported that high levels of glycosaminoglycans (GAGs) are found after free radical injury (Campo GM et al., Chem Biol Interact, 148: 125, 2004). The addition of hyaluronic acid (HA) was able to protect cells from oxidative stress. These outcomes were positive by using both commercial HA and purified plasma GAGs of human origin (Campo GM et al., Free Radic Res, 38: 601, 2004; Campo GM et al., Toxicol In Vitro, 19: 561, 2005). HA synthesis is regulated by three hyaluronan sinthases (HAS1, HAS2 and HAS3). Recently it has been reported that several cytokines such as interferon- $\gamma$ (IFN- $\gamma$ ), tumor necrosis factor- $\alpha,($ TNF- $\alpha$ ), etc. are able to modulate HASs transcription in cell cultures (Stuhlmeier KM and Pollaschek C, J Biol Chem, 279: 8753, 2004). The net consequence of this modulation is an increase in $\mathrm{HA}$ levels. The aim of this research was to evaluate the protective effects of the increased endogenous HA concentration, obtained by using cytokines stimulation, in fibroblast cultures exposed to oxidative stress. IF $N-\gamma$ and TNF- $\alpha$ were added to the fibroblast cultures before oxidative stress induction by using the oxidizing system employing $\mathrm{Fe}^{2+}$ plus ascorbate. We assessed $\mathrm{HASI}$, HAS2 and HAS 3 mRNA content, HA levels, cell death, lactate dehydrogenase activity, membrane lipid peroxidation, and endogenous antioxidant depletion. The treatment of fibroblasts with cytokines up-regulated HASs gene expression and increased HA production, while the exposure of the cultures to $\mathrm{Fe}^{2+}$ produced cell death, enhanced lipid peroxidation and lactate dehydrogenase activity and decreased antioxidant defences. The effect of the endogenous increase of $\mathrm{HA}$, induced by the cytokines, to protect cell from oxidative injury is especially discussed. 
The effect of glycosaminoglycan and proteoglycan addition to murine chondrocytes in culture on gene expression of matrix metalloproteinases (MMPs) and their tissue inhibitors (TIMPs)

S. Campo, A. D'Ascola, G.M. Campo, A. Avenoso, A.M. Ferlazzo, ${ }^{1}$ A. Lania, A. Calatroni

Department of Biochemical, Physiological and Nutritional Sciences, 'Department of Morphology, Biochemistry, Physiology, Animal Production, University of Messina, Italy

The functional integrity of articular cartilage is determined by a balance between chondrocyte biosyntesis of extracellular matrix and its degradation. The matrix metalloproteinases (MMPs) constitute a family of secreted/cell-surface-anchored zinc endopeptidases, which are essential mediators of normal tissue remodelling as well as of tissue destruction in both inflammatory and degenerative joint diseases. The proteolytic activity of the MMPs is normally regulated by endogenous specific inhibitors, tissue inhibitors of metalloproteinases (TIMPs). In this study we examined the effect of murine chondrocytes culture treatment with commercial Glycosaminoglycans (GAGs: Hyaluronan, HA, Chondroitin-4-sulphate, C-4-S, Chondroitin-6-sulphate, C-6-S, Dermatan sulphate, DS) and purified human plasma Proteoglycan (PG) preparation (mainly composed of C-4-S PGs) on the gene expression of MMPs ( MMP1a, MMP1b, MMP2, MMP3, MMP8, M MP9, MMP13, MMP14, MMP16), TIMPs (TIMP1, TIMP2, TIMP3 and TIMP4), ILI $\beta$ and TGF $\beta$. GAGs are expected to affect matrix biosynthesis; plasma PGs are considered breakdown product of cartilage metabolism. A dose dependent effect was studied by using three different amounts for each additive product. Furthermore, the mRNAs transcription was evaluated at 24 and 48 hours. The addition, to the chondrocytes cultures, of commercial HA and plasma PGs preparation showed a more evident effect with respect to the other molecules. The HA handling, in a dose dependent way, increased MMP8 and MMP9 gene expression, while purified plasma $P G s$ treatment increased both MMP3 and MMP9 mRNA levels with no apparent dose effect.

\section{Integrin and laminin chain expression in alpha 7 deficient smooth muscular tissue}

M. Contin, ${ }^{1}$ A. Bonetti, ${ }_{1}^{1}$ M. Marchini, ${ }^{1}$ U. Mayer $_{,}{ }^{2}$ L. Sorokin ${ }^{3}$ K. von der Mark, ${ }^{4}$ F. Ortolani ${ }^{1}$

${ }^{1}$ Dept. Med. Morphol. Res., University of Udine, Italy; ${ }^{2}$ Wellcome Trust Centre for Cell -Matrix Research, University of Manchester, UK; ${ }^{3}$ Dept. Exp. Pathol., University of Lund, Sweden; ${ }^{4}$ Dept. Exp. Med., Nikolaus-Fiebiger Center Molecular Medicine, University of Erlangen, Germany

In muscular tissues, alpha7betal is the major integrin receptor for laminins, which are represented by isoforms laminin 2 and 4 (basal laminae of skeletal and cardiac muscle cells) 8 and 10 (smooth muscle cell basal laminae). The absence of alpha7 integrin chain leads to the onset of skeletal muscular dystrophies (Mayer U et al., Nature Genet 1997, 17, 318), and cardiac hypertrophy (Ortolani $\mathrm{F}$ et al., in press). In alpha 7 integrin chain deficient mice, we previously observed different degrees of ultrastructural alteration between viscera wall smooth muscle cells of those in vascular walls. Since moderate up-regulation of alpha 5 integrin chain was described for alpha 7 deficient skeletal muscle (Nawrotzki R et al., Hum Mol Genet 2003, 12, 483), here compensatory overexpression was investigated of other alpha integrin chains and laminins in alpha 7 deficient mice, concerning smooth muscle cells of muscularis externa of oesophagus, stomach, ileus, colon, bladder, uterus as well as those in tunica media of vessels of the heart, different skeletal muscles, and viscera walls as above. No differences appeared for alpha 5 and alpha 6 integrin chain distribution pattern in both control and K.O. mice, whereas remarkable increase in alpha 3 integrin chain was apparent in K.0. smooth muscle cells versus control ones, more evident in viscera walls than in vascular ones, consistently with the weaker damage observed. Concerning the distribution of laminin chains, no differences was detected by comparing w/t and K.O. mice. Hyperforin inhibits PMN migration, inflammation-trig-
gered angiogenesis and pulmonary fibrosis

I. Dell'Aica, ${ }^{1}$ F. Piazza, ${ }^{2}$ L. Sartor ${ }_{1}{ }^{1}$ C. Colalto, ${ }^{1}$ E. Brunetta, ${ }^{2}$ G. LoRusso, ${ }^{3}$ R. Benelli, ${ }^{3}$ A. Albini, ${ }^{3}$ F. Calabrese,${ }^{4}$ C. Agostini, ${ }^{2}$ S. Garbisa ${ }^{1}$

${ }^{1}$ Dept. Experim. Biomedical Sciences, University of Padova; ${ }^{2}$ Dept. Clinical Medicine I, University of Padova; ${ }^{3}$ Molecular Biology Laboratory, IST, Genova; ${ }^{4}$ Dept. Pathology, University of Padova, Italy

Hyperforin (Hyp), a polyphenol-derivative of St. John's Wort, has emerged as key player in the anti-depressant activity of the plant, but also as inhibitor of bacteria, lymphocyte and tumorcell proliferation, and matrix proteinases. We tested whether, besides inhibition of LE activity, Hyp might efficaciously contain both polymorphonuclear (PMN) leukocyte recruitment and unfavorable eventual tissue responses. The study analyzed human PMN-conditioned media by gelatin zymography, PMN chemotaxis and chemoinvasion through gelatin and Matrigel, expression of PMN chemokine-receptors and integrins by cytofluorimetry, inhibition of PMN-triggered angiogenesis in an IL8 -induced murine model, restraint of inflammation-triggered lung fibrosis in a bleomycin-induced murine model. Without affecting PMN viability, chemokine receptor or CD1lb/CD18 integrin array, the compound exerts efficient dose-dependent restrain of their chemotaxis and chemoinvasion (IC50 $1 \mu \mathrm{M}$, for both), blocking the LE-triggered activation of the extravasation-instrumental gelatinase MMP-9, preserving its zymogen form from spontaneous rapid turnover, and up-modulating $\mathrm{ERK} 1 / 2$ activation. PMN-mediated angiogenesis in vivo is blocked by both local injection, and daily i.p. administration of Hyp; the latter protocol enhances resolution in a pulmonary inflammation model, significantly reducing consequent fibrosis. These results indicate that Hyp is a potent anti-inflammatory compound with therapeutic potential, and shed light on mechanistic keys.

\section{The 3D structure of crimps in stretched and relaxed collagen fibers of rat gastrocnemius tendon}

M. Franchi, ${ }^{1}$ M. Quaranta, ${ }^{1}$ M. Raspanti, ${ }^{2}$ V. De Pasquale, ${ }^{1}$ V. Ottani, ${ }^{1}$ M. Fini, ${ }^{3}$ G. Giavaresi, ${ }^{3}$ A. Ruggeri ${ }^{1}$

${ }^{1}$ Department S.A.U.F.A.L. Human Anatomy, University of Bologna; 'Department of Human Morphology, Insubria University of Varese; ' ${ }^{2}$ aboratory of Experimental Surgery, Codivilla-Putti Research Institute-Rizzoli Orthopedic Institute, Bologna, Italy

Stretching training enhances joint range of motion and is recommended to improve performance during human movements and prevent tendon and muscle injuries. ${ }^{1}$ No in vivo morphological study has been carried out on tendon stretching both in humans or animals. In this study we reproduced the in vivo mechanical conditions of a static stretching single training applied to gastrocnemius muscle and Achilles tendon of six rats (Sprague Dawley) 3 months old. A resin adapted tutor was applied to a posterior leg of each animal kept under anaesthe- 
sia dorsally flexing the foot of $55^{\circ}$ for 10 minutes. Achilles tendon of the controlateral leg was kept relaxed as control. Tendons of both legs were fixed in Karnovsky solution and then excised to be processed for direct light microscopy (DLM), polarized light microscopy (PLM), scanning electron microscopy (SEM) and transmission electron microscopy (TEM). Control tendons showed at DLM, PLM, SEM and TEM parallel wavy collagen fibres corresponding to collagen crimps described in literature as helical structures, flattened helices, spirals or smooth waves. Control crimps (angle of $7^{\circ}$ ) were morphologically studied. ${ }^{2}$ In stretched tendons crimps (angle of $7^{\circ}$ ) almost disappeared. The mechanism of elongation of tendon during stretching consists in an almost complete disappearance or evident flattening of crimp structures. In fact, when present, crimps of stretched tendon showed a reduction of the angle of about $40 \%$ vs. control crimps.

\section{References}

1. Kubo K. et al., J Appl Physiol 2001, 90, 520-7.

2. Magnusson SP. et al., Matrix Biol 2002, 21, 369-77.

Supported by the grant MIUR COFIN 2004.

\section{Hyaluronan metabolism in in vitro culture of endothelial cells}

A. Genasetti, P. Moretto, D. Vigetti, M. Viola, M. Rizzi,

E. Karousou, F. Pallotti, A. Passi, G. De Luca

DSBSC, Università dell'Insubria, Varese, Italy

Hyaluronan (HA) is a non sulphated glycosaminoglycan present in extracellular matrix and it is involved in a variety of physiological processes, such as cellular growth, migration and tumor progression. The mechanisms underlying the overproduction of HA by stroma cells surrounding tumors have not been completely elucidated. The biosynthesis of $\mathrm{HA}$ is regulated by three mammalian HA synthases, HAS1, HAS2 and HAS3, that differ from each other in the expression profile in embrionic development and in their ability to form HA with different lenght. As eucariotic cells show different efficiency in HA production, we have established a model to compare two vein endothelial cells cultures in vitro (ECV, immortalized cell from endothelial vein and HUVEC, human umbilical vein endothelial cells). ECV and HUVEC (Cambrex) have been cultured in complete EGM2 medium according to protocols. To measure the HA production, conditioned media were collected and analysed by electrophoresis technique (FACE). From each cultures we extracted the HA cytoplasmatic precursors (UDPsugars) using Triton X-100 and acetonitrile and we separated UDP sugars by capillary electrophoresis. Gene expression studies were carried out by Taqman RealTime RT-PCR on total RNA extracted from ECV and HUVEC in order to study the gene expression of $\mathrm{HA}$ synthases, hyaluronidases (Hyal) and HA membrane receptor CD44. Using membrane impedence quantification we valuated cell migration ability.

Culture medium of ECV has been found to have higher HA content than HUVEC whereas UDP-sugars showed similar concentration. Gene expression experiments have shown a substantial induction of the mRNA coding for only HAS3 in ECV. As the induction of HA degrading enzymes in ECV have been slighter than HAS3 increase, the HA accumulation in these cells could mainly depends on HAS3 up regulation rather than Hyal down regulation in ECV. Moreover, the higher level of HA in ECV correlated with an elevated migratory capacity of this cells. $\beta 2$-microglobulin isoforms display an heterogeneous affinity for type I collagen

S. Giorgetti, ${ }^{1-2}$ A. Rossi, ${ }^{1}$ P. Mangione, ${ }^{1}$ S. Raimondi, ${ }^{1-2}$

S. Marini, ${ }^{1-2}$ M. Stoppini, ${ }^{1}$ A. Corazza, ${ }^{3}$ P. Viglino, ${ }^{3}$ G. Esposito, ${ }^{3}$ G. Cetta, ${ }^{1}$ G. Merlini, ${ }^{1-2}$ V. Bellotti ${ }^{1-2}$

${ }^{1}$ Dipartimento di Biochimica, Università di Pavia; ${ }^{2}$ Biotechnology Laboratories IRCCS, Policlinico San Matteo, Pavia; ${ }^{3}$ Dipartimento di Scienze e Tecnologie Biomediche Università di Udine, Italy

Amyloidosis associated with long term haemodialysis (DRA) is caused by fibrillar deposition of $\beta 2$-microglobulin $(\beta 2-\mathrm{m})$ and it is localized in muscle skeletal system. It has been claimed that $\beta 2-m$ interacts with type I and type II collagen and this property has been linked to deposits tissue specificity. The binding parameters of the interaction between collagen and $\beta 2-m$ were determined by band shift electrophoresis and surface plasma resonance by using bovine collagen of type I and various isoforms of $\beta 2-\mathrm{m}$. Wild type $\beta 2-\mathrm{m}$ binds collagen type I with a $K_{d}$ of $4.1 \times 10^{-4} \mathrm{M}$ and type II with $2.3 \times 10^{-3} \mathrm{M}$. By the BIAcore ${ }^{\mathrm{TM}}$ system we monitored the binding properties of the conformers of the slow phase of folding of $\beta 2-m$ (Chiti et al. 2001 J. Mol. Biol. 307:379-391). The folding intermediates during the slow phase of folding don't display any significant difference with respect to the binding properties of the fully folded molecule. Increased affinity for collagen type I is found in the case of $\mathrm{N}$-terminal truncated species lacking of six residues. The $\mathrm{K}_{\mathrm{d}}$ of this species is $3.4 \times 10^{-5} \mathrm{M}$ at $\mathrm{pH} 7.4$ and its affinity increases to $4.9 \times 10^{-6} \mathrm{M}$ at $\mathrm{pH} 6.4$ (Giorgetti et al. Protein Sci. 2005 14:696-702). Fluctuations of the affinity caused by $\beta 2-\mathrm{m}$ truncation and $\mathrm{pH}$ change can cause modifications of protein concentration in the solvent that surrounds the collagen and could contribute to generate locally a critical protein concentration able to prime the protein aggregation.

\section{Human recombinant prolidase: synthesis, purification and characterization}

A. Lupi, S. Della Torre, F. Curtoni, R. Tenni, G. Cetta, A. Rossi, A. Forlino

Dipartimento di Biochimica "A. Castellani", Università di Pavia, Italy

Prolidase is a dipeptidase involved in the latter stage of proteins catabolism. It hydrolyses imidodipeptides containing proline or hydroxyproline at the C-terminal position. Mutations in the prolidase gene (PEPD) cause Prolidase Deficiency (PD), an autosomal recessive connective tissue disorder. The enzyme structure, catalytic site and kinetic are still mainly unknown as well as the genotype-phenotype relationship in PD.

We generated a recombinant human prolidase in eukaryotic $(\mathrm{CHO})$ and prokaryotic (E.Coli) systems. Total RNA from human fibroblasts was extracted, retrotrascribed, PCR amplified with specific prolidase primers and subcloned respectively in pcDNA4HisMax and pET16b+ vectors, both containing an $\mathrm{N}$-terminal poliHis Tag. The enzyme was purified by affinity chromatography using the Ni-NTA Agarose resin and a step imidazole gradient from 50 to $500 \mathrm{mM}$. Enzyme activity and Western Blotting with Anti His antibody were used to follow the purification. Both recombinant enzymes had temperature and $\mathrm{pH}$ range of activity similar to human fibroblasts prolidase, with a maximum at $50^{\circ} \mathrm{C}$ and $\mathrm{pH} \approx 8$. They showed also similar inhibition susceptibility to Cbz-Pro and similar long term stability at $37^{\circ} \mathrm{C}$. Enzymatic digestion of the $\mathrm{His}$ Tag results in an increase of activity, but did not alter the other parameters. Western blotting on cytosolic and nuclear fractions of $\mathrm{CHO}$ transfected cells and confocal microscopy demonstrated a cytosolic localization of the prolidase enzyme. 
In conclusion the recombinant enzyme reproduces the biochemical characteristic of the human enzyme representing a valid tool to better investigate and characterize this enzyme and to develop an enzyme replacement therapy for human PD.

Work Supported by Italian MIUR Grant n. 200352778 and CIB 2003.

\section{Characterization of ECM scaffolds obtained by decellularization of bovine nasal cartilage}

F. Naso, M. Marchini, ${ }^{1}$ F. Ortolani, ${ }^{1}$ A. Gandaglia, M. Spina Department of Experimental Biomedical Sciences, University of Padova; 'Department of Medical and Morphological Research, University of Udine, Italy

The object of this study is the characterization of scaffolds obtained by decellularization of bovine nasal cartilage. The aim is to prepare intact structured ECM scaffolds with increasing porosity which in turn could act as substrate for repopulation with condroblasts.

Such scaffolds have been prepared removing cell components by combining ipotonic conditions in presence of protease inhibitors followed by detergent like Tris and Deoxycholate (TRIDOC). By an alternative procedure samples were previously treated with $0.9 \mathrm{M}$ Urea (U-TRIDOC). The porosity of the system was tentatively increased by subsequent partial removal of GAG with testicular hyaluronidase. Residual scaffolds were analysed for collagen, uronate and water content and finally observed by TEM.

Hyaluronidase removes $33 \%$ of total dry weight from original untreated samples (NT), while TRIDOC and U-TRIDOC 32 and $23 \%$, respectively, when followed by hyaluronidase. Thus pretreatment with urea apparently stabilizes the matrix by reducing the amount of material solubilized by hyaluronidase itself. This material is composed by collagen and accounts to about $10 \%$ of the initial dry weight. Hyaluronidase solubilizes $25 \%$ of total uronate from NT sample and 35 and $34 \%$ when in combination with TRIDOC and U-TRIDOC, taking into account, however, that 33 and $32 \%$ of total uronate had already been removed by detergent treatment, respectively. When examined by TEM cells appear to have been removed from ECM lacunae.

In addition to cells, detergents remove significant amount of collagen and GAG by themselves. Pretreatment with urea prevents the specific removal of collagen following hyaluronidase treatment but does not influence its action on GAG.

\section{Physiological and pathological aspects of the shape modular structure of cartilage, involving decorans. The aetiology of osteoarthritis}

J.E. Scott

Chemical Morphology, Manchester University Medical School, Manchester, U.K.

The extracellular matrix (ECM) shape module concept has evolved through successive stages; Morphological demonstration of regular interfibrillar bridges of lengths characteristic of the ECM, present in all non-mineralised ECMs; Biochemical identification of decorans non-covalently attached at specific binding sites to collagen fibrils via decoron proteins with antiparallel dermochondan sulphate (DS) aggregates bridging the fibrils; Physiological, contributing vital elasticity to the ECMs. ${ }^{1}$ What pathologies are there?

Cartilages are built of shape modules, explaining for the first time anisotropic responses of articular cartilage to compressive and tensile stresses. ${ }^{2}$ Degradation of shape modules in osteoarthritis, the major crippling disease, reduces these responses. Loss of shape modular function in binding together collagen fibrils via decoran bridges, results in sucking-in of water as fibrils drift apart under the swelling pressure of the aggrecan, etc. Elastic decoran helps to define and maintain cartilage shape whereas expansile aggrecan has less influence on morphology. DS contains L-iduronate, a sugar that switches elastically between conformers of different lengths under tension. ${ }^{3}$ Stanescu claimed loss of a decoran-like PG in osteoarthrotic cartilage. Decoran may be a primary target of the $O A$ disease process.

\section{References}

1. Scott JE. Elasticity in extracellular matrix 'shape modules' of tendon, cartilage etc. A sliding proteoglycan-filament model. J. Physiol 2003;553:335-43.

2. Scott JE \& Stockwell RA. 2005, In press.

3. Haverkamp RG, Williams MAK, Scott JE. Stretching individual molecules of connective tissue glycans to characterise their shape-maintaining elasticity. Biomacromol. 2005; 6:1816-8.

\section{Molecular effects of glucosamine and its derivative on cartilage homeostasis}

A. Scotto $d^{\prime}$ Abusco,${ }^{1}$ C. Cicione ${ }^{1}$ R. Negri, ${ }^{2}$ O. Moreschini ${ }^{3}$

B. Grigolo, ${ }^{4}$ L. Politi, ${ }^{1}$ R. Scandurra ${ }^{1}$

${ }^{1}$ Dip. Scienze Biochimiche, ${ }^{2}$ Lab. Genomica Funzionale e Proteomica Sistemi Modello, ${ }^{3}$ Dip. Scienze dell'Apparato Locomotore, Università "La Sapienza", Roma; "Lab. Immunologia e Genetica, Ist. Ortopedici Rizzoli, Bologna, Italy

Introduction. Glucosamine (GS), a symptom-control drug, was found to entail also joint structural changes in Osteoarthrosis. We report the effects of GS and its derivative N-Acetyl Phenylalanine Glucosamine (NAPA) on an immortalized chondrocyte cell line LBPVA 55 (Osteoarthritis and Cartilage, 2002, 10:879) to explain the in vitro results previously obtained (Eur. J. Med. Chem. 1991, 26:753). Methods. LBPVA 55 cells were stimulated with TNF $\alpha(10 \mathrm{ng} / \mathrm{mL})$ and treated with GS and NAPA at $0.25 \mathrm{mM}$ and $10 \mathrm{mM}$ respectively, the latter mimicking therapeutic concentration. mRNA expression was analysed by cDNA microarray and by Quantitative Real Time PCR (Q-RT-PCR). Results and discussion. A number of genes, analyzed by microarray, were up-regulated by TNF $\alpha$ and modulated by GS and NAPA. To confirm the microarray results, Q-RT-PCR analysis was performed. Only $15 \%$ of genes detected by microarray showed the same trend with Q-RT-PCR, probably due to difference in sensitivity of the two methods. TNFR1, a receptor for TNF $\alpha$ and TRAF6, a molecule involved in TNF $\alpha$ pathway, resulted up-regulated by TNF $\alpha$ and modulated by GS and NAPA. Cullin2, rho6, a small GTPase, IL-1 $\beta$ and IL-6 mRNA expression was modulated as well. At NAPA and GS $10 \mathrm{mM}$ concentration, ILI $\beta$ resulted modulated by GS, but not by NAPA, whilst NAPA gave greater modulation of TNFR1, TRAF6 and rho6. We previously demonstrated that both drugs successfully re-organize articular cartilage in vivo (XIX FECTS, 2004, PMI1), and now our findings assess that they affect gene expression of proteins involved in inflammatory cascade and cartilage homeostasis. 
Identification of free decorin core protein in tendon M. Sonaggere, B. Bartolini, F. Barbieri, R. Tenni, M.E. Tira Dipartimento di Biochimica "A. Castellani", Università di Pavia, Italy

Decorin is a multifunctional proteoglycan expressed in the extracellular matrix of any connective tissue and its functions are correlated to the biological activity of both the core protein and the glycosaminoglycan moiety. It is known that decorin core protein is able to bind several molecules such as fibronectin, thrombospondin and TGF $\beta$, so it is of relevant interest try to identificate the eventual presence of the free core in the tissues, besides the mature form, to define the correct biological potentiality of the proteoglycan. Decorin was purified from bovine tendon; the whole proteoglycan and the GAG-free decorin core were obtained by $4 \mathrm{M}$ guanidine hydrochloride extraction of tendons, ultracentrifugation in $\mathrm{CsCl}$ gradient and DEAE Sephacel chromatography. The identity of the GAG-free core was determined by western blotting stained with policlonal anti decorin antibody and its migration pattern was similar to the one obtained after ABCase treatment of the mature form of the proteoglycan. Roughly, the weight ratio between GAG-free core and the whole decorin was 1:10. We are now performing preliminary binding studies of the native core protein with acid-soluble type I collagen and pepsinized type II collagen, in order to compare the preparation with the core protein obtained by enzymatic digestion of the glycosylated proteoglycan. Moreover, it will be interesting to determine the variation of the free core protein content in different physiological and pathological conditions.

Work Supported by University of Pavia and MIUR (PRIN 2003055193 and 2004055533).

\section{Molecular cloning and characterization of UDP-glucose dehydrogenase from the amphibian Xenopus laevis and its involvement in hyaluronan synthesis}

D. Vigetti, ${ }^{1}$ M. Viola, ${ }^{1}$ A. Genasetti, ${ }^{1}$ E. Karousou, ${ }^{1}$ F. Pallotti, ${ }^{1}$ V.C. Hascall, ${ }^{2}$ G. De Luca, ${ }^{1}$ A. Passi ${ }^{1}$

${ }^{1}$ Dip. di Scienze Biomediche Sperimentali e Cliniche, Università degli Studi dell'Insubria, Varese, Italy; ${ }^{2}$ Department of Biomedical Engineering and Orthopaedic Research Center/ND20, The Cleveland Clinic Foundation, Cleveland, Ohio, USA

UDP-glucose dehydrogenase (UGDH) supplies the cell with UDP-glucuronic acid, a precursor of glycosaminoglycan and proteoglycan synthesis. In our study, we cloned and characterized the UGDH from the amphibian Xenopus laevis that is one of the model organisms for developmental biology. We found that Xenopus UGDH ( $x \cup G D H)$ maintained a very high degree of similarity with other known UGDH sequences both at the genomic and the protein levels. Also its kinetic parameters are similar to those of UGDH from other species. During $X$. laevis development, UGDH is always expressed, but clearly increases its mRNA levels at the tailbud stage (i.e., 30 hours post fertilization). This result fits well with our previous observation that hyaluronan, a glycosaminoglycan that is synthesized using UDP-glucuronic acid and UDP-N-acetyl glucosamine, is abundantly detected at this developmental stage. The expression of UGDH was found to be related to hyaluronan (HA) synthesis, in fact in human smooth muscle cells the overexpression of $x U G D H$ or endogenous abrogation of UGDH altered UDP sugar concentration in cells and modulated specifically HA synthesis. Our findings were confirmed by in vivo experiments where the silencing of $x U G D H$ in Xenopus embryos determined a HA decreased and a severe malformations at neural tube during early development.
Effects of EPO on the structural recovery of the nervous tissue in a rat model of traumatic spinal cord injury L. Vitellaro Zuccarello, S. Mazzetti, P. Bosisio, S. De Biasi Dipartimento di Scienze Biomolecolari e Biotecnologie, Università degli Studi di Milano, Italy

Recent studies have shown that the acute administration of recombinant human erythropoietin (rhEPO) attenuates the effects of traumatic spinal cord injury and accelerates functional recovery in a rat experimental model (Gorio et al., PNAS 99:9450-9455, 2002). Our investigation aimed at elucidating the mechanisms, at present largely unknown, through which EPO exerts its beneficial actions. Since the formation of a glial scar enriched in chondroitin sulfate proteoglycans (CSPGs) has a repulsive effect on axonal regrowth and compromises functional outcome, we investigated whether rhEPO reduces the extension of the glial scar and influences the expression of CSPGs. To this end, we applied immunocytochemical methods at light and confocal microscopy to study the distribution of neurocan, aggrecan and versican in the spinal cord of rats at 30 days after contusive spinal cord injury, with or without rhEPO administration. Our results showed that, in comparison to controls, in the injured spinal cords 1) all the molecules considered were upregulated throughout the whole grey and white matter, and not only at the lesion site; 2 ) the administration of rhEPO did not significantly modify their levels, although it significantly reduced the size of the glial scar, the extent of the gliosis and the amount of macrophages and microglia. The complex of the results indicates that rhEPO does not influence the expression of CSPGs considered in the present study, but exerts an anti-inflammatory effect that improves the structure of the nervous tissue by reducing the extent of the secondary damage.

\section{(Supported by COFIN grant)}




\section{CONNECTIVE TISSUE DISEASES AND CANCER}

\section{Calcification in human stenotic aortic valves: involvement of acidic lipids and annexin- $V$}

A. Bonetti, ${ }^{1}$ U. Livi, ${ }^{2}$ V. Tursi, ${ }^{2}$ M. Contin, ${ }^{1}$ M. Marchini, ${ }^{1}$

F. Ortolani ${ }^{1}$

${ }^{1}$ Department of Medical Morphological Research, University of Udine; ${ }^{2}$ Cardiothoracic Surgery Unit, S. Maria della Misericordia Hospital of Udine, Italy

Acidic lipid clustering at the surface of cells and matrix vesicles and associated calcium-binding protein Annexin-V (Anx$V$ ) have been found to act as major apatite nucleators in aortic valves subjected to experimental calcification (Ortolani $\mathrm{F}$ et al., Connect Tissue Res 43: 44-55, 2002; Histochem J 34: 4150, 2002; Histol Histopathol 18: 1131-40, 2003). Here, possibility was investigated that these degenerative processes also occur in pathological valve calcification.

After explantation, human calcified valves affected by aortic stenosis were subjected to reaction with $0.05 \%$ Cuprolinic Blue $+2.5 \%$ glutaraldehyde $+0.05 \mathrm{M} \mathrm{MgCl}_{2}$ in phosphate solutions, pH 4,8 (GA-CB). Semithin sections of GA-CB-reacted samples underwent von-Kossa-silver-staining and re-embedded to achieve reacted thin sections (GA-CB-S). Histological sections underwent von-Kossa-silver-staining ( $\mathrm{S}$ ). Cryosections underwent immunohistochemical reactions for Anx-V. LRWhite-thin sections underwent immunogold reactions for Anx$V$. Polyclonal AB anti-Anx-V R88 was used (courtesy of Klaus von der Mark).

As for experimental valve calcification, it was observed clustering of acid lipids around cell debris, matrix vesicles and elastic fibers, colocalization between GA-CB and GA-CB-S reactivity, and immunogold labelling for $A n x-V$ which was closely associated with the accumulating lipidic material.

These results suggest common mechanisms to be shared by this pathological calcification and experimental one, including initial hypoxia-induced up-regulation of Anx-V (Denko N et al., Clin Cancer Res 6: 480-7, 2000) and subsequent translocation due to protein avidity for the exudating lipids.

\section{On the pathogenesis of PXE-like clinical manifestations in $\beta$-thalassemia patients}

F. Boraldi, C. Paolinelli DeVincenzi, M.I. Garcia-Fernandez, D. Quaglino, R. Tiozzo, M.A. Croce, P. Cianciulli, ${ }^{1}$ F. Sorrentino, ${ }^{1}$ G.L. Forni, ${ }^{2}$ I. Pasquali Ronchetti

Dept. of Biomedical Sciences, University of Modena and Reggio Emilia, Modena; ${ }^{1}$ Ospedale S. Eugenio, Tor Vergata, Roma; ${ }^{2}$ Microcyt., Congen. Anaemias Ctr, Ospedali Galliera, Genova, Italy

A number of $\beta$-thalassemia patients, with no mutations in the ABCC6 gene, have clinical and histological connective tissue alterations almost identical to those in genetic PXE. In vitro dermal fibroblasts from $\beta$-thalassemia patients with $(P X E+)$ and without (PXE-) PXE-like alterations were compared with those from genetic PXE and from controls as to their redox balance and ability to accumulate and to extrude calcein, a marker used to evaluate the efficiency of MDR/MRP membrane transporters. Cells from $\beta$-thal-(PXE+) behave as those from genetic PXE, since they have an higher level of vitamin E-sensitive ROS compared to controls and to $\beta$-thal(PXE-) cells. Moreover, $\beta$-thal-(PXE +$)$ cells accumulate significantly more and release significantly less calcein compared to controls and to $\beta$-thal-(PXE-) cells, revealing a behaviour almost identical to cells from PXE. These findings indicate that $\beta$-thal- $(P X E+)$ cells suffer from a mild oxidative stress and have an impaired function of MRP/MDR transporters similar to that in PXE. However, the effect of inhibitors (indomethacin, benzbromarone, MK571) of calcein release is different in PXE and in $\beta$-thal-(PXE+) cells, suggesting that the MRP/MDR deficiency in $\beta$-thal- $(P X E+)$ cells is due to different mechanisms compared to that in PXE. This agrees with the datum that ABCC6 gene and expression are normal in $\beta$-thal-(PXE+) cells and indicate that the impaired transport activities may depend on other genes and/or epigenetic factors. In conclusion, data suggest that PXE-like clinical manifestations in $\beta$-thalassemic patients could depend on an oxidative stress associated with or causing a deficient activity of membrane transporters, leading to metabolic alterations similar to those in PXE.

Financial support from MIUR (2004064073-001), EC 6th Progr CA GENESKIN (512117), and PXE-Intern.

\section{Cross-talk between breast cancer cells and fibroblasts in coculture system}

P. Cancemi, M.R. Marabeti, N. Albanese, S. Caricato,

S. Minafra, I. Pucci Minafra

Università di Palermo, Dipartimento di Oncologia Sperimentale e Applicazioni Cliniche, Centro di Oncobiologia Sperimentale, Dip. Oncologico 'La Maddalena', Palermo, Italy

Among solid tumors, breast cancer is one of the most frequent and potentially aggressive forms. The transition from a benign to a malignant tumor is correlated to cell invasion through the basal lamina. In this phase, several cascade processes start to be activated, involving the progressive transition of the epithelial phenotype (stationary and polarised) into a mesenchymal motile phenotype. In the mean time, the host stroma undergoes severe changes, including ECM modifications and host cell's recruitment. Therefore, the extracellular environment of primary tumors may be depicted as a complex microecosystem, in which the neoplastic cells, the extracellular matrix, mesenchymal cells, blood and lymphatic vessel, and a variety of active factors play a dynamic role in the progression of the cancer.

Between host cells of the tumor microenvironment, fibroblasts are likely to be the most representative ones. To investigate the possible interactions between neoplastic cells and fibroblasts we have performed proteomic analyses of breast cancer cells (8701-BC) cocultured with normal fibroblasts.

In the coculture experiments the two cell types were grown separated by a microporous membrane. The protein profiles were obtained by 2D-IPG and identified by Nt-microsequencing, Maldi-Tof and Western Blot. The spots, with assigned identity, were grouped into functional categories, as previously described (Pucci Minafra et al. Annals NY Acad. Sci. 963: 122-139, 2002). The comparative analysis between control and cocultured cells revealed significant variations of the expression levels especially with regards to cytoskeletal proteins. In particular an increased expression level of vimentin and a decrease of cytokeratins were observed. These data might be related to a more marked epithelium-mesenchyme transition and/or an increase in the motility of $8701 / B C$ cells when cocultured with fibroblasts.

Work supported by MIUR cofin to I.PM 2004. 
Homozygosity modulates OI phenotype in BrtlIV mouse A. Forlino ${ }^{1,2}$ C. Bergwitz, ${ }^{1}$ T.E. Uveges, ${ }^{1}$ K.M. Kozloff, ${ }^{3}$ N.V. Kuznetsova, ${ }^{4}$ G. Gronowicz, ${ }^{5}$ S.A. Goldstein, ${ }^{3}$ S. Leikin, ${ }^{4}$ J.C. Marini ${ }^{1}$

${ }^{1} B E M B, \quad N I C H D, N I H$, Bethesda, USA; ${ }^{2}$ Dept of Biochemistry, University of Pavia, Italy; ${ }^{3}$ Ortho Res Labs, $U$ Mich, Ann Harbor, MI, USA; ${ }^{4}$ Sect of Phys Biochem, NICHD, NIH, Bethesda, USA; ${ }^{5} \mathrm{U}$ Conn Health Center, Farmington, CT, USA

Brtl mouse is a murine model for Osteogenesis Imperfecta generated by knocking a G349C substitution into one collal allele. Brtl/+ pups have $30 \%$ perinatal lethality. Surviving Brtl mice are small, with weaker and more brittle bones than WT.

By mating the Brtl/+ mice we made the surprising observation that the OI phenotype was milder in Brtl/Brtl homozygous mice. Brtl/Brtl have normal perinatal survival rate and their weight and size is intermediate between WT and Brtl/+. They lack the rib fractures and flared thorax, as well as the vertebral and calvarial demineralisation seen in Brtl/4. Brtl/Brtl 2 month femurs have normal BMD and intermediate CSA, $\mathrm{BV} / \mathrm{TV}$ and $\mathrm{Tb} T h$, withstand normal loading to fracture and are less brittle than Brtl/+. Cell numbers, MAR and BFR/BS were unchanged at 2 and 6 months, compared to WT.

Matrix insufficiency and collagen chain composition may contribute to the difference in phenotype between animals with different genotype. In Brtl/+, type I collagen with one mutant chain is selectively retained by the cells, whereas the collagen with two mutant chains is better secreted. Since Brtl/Brtl mice make exclusively collagen with two mutant $\alpha 1$ (I) chains, this results in a $33 \%$ matrix insufficiency in homozygotes vs the $40 \%$ insufficiency in heterozygous. Additionally, the reactive $\mathrm{SH}$ group in $\mathrm{Brtl} /+$ type I collagen might form illegitimate cross-links with intracellular or matrix components. We are investigating the relative importance of matrix insufficiency and collagen composition to phenotype modulation.

\section{ABCC6 gene analysis in Italian subjects affected by Pseudoxanthoma elasticum}

D. Gheduzzi, E. Giacobazzi, M. Rebecchi, R. Guidetti, D. Quaglino, I. Pasquali Ronchetti

Department of Biomedical Sciences, University of Modena and Reggio Emilia, Modena, Italy

Pseudoxanthoma elasticum (PXE) is a genetic disorder due to mutations in the ABCC6 gene, a member of the ABC subfamily of membrane transporters, characterized by high genetic heterogeneity. More than 80 different mutations have been identified; a few of them are recurrent mutations, the majority are sporadic mutations. The analysis of the 31 exons and of the flanking intron sequences of the gene is often required for mutational screening.

In order to identify mutations in the Italian PXE families, to characterize Italian genotypes and to expand the mutational spectrum of the gene, we developed an efficient strategy for DNA diagnosis of PXE by combining different methodological approaches.

A cohort of 83 Italian PXE families was examined. The two most frequent mutations, p.R1141X and ABCC6 E23_29del, as well as deletion ABCC6 E15del, were identified by restriction enzyme digestion ( $p . R 1141 X$ ) or selective amplification with specific primers (ABCC6 E23_29del, ABCC6 E15del) and size separation on agarose gels. In a number of patient, where only one or no mutant allele was found, the direct sequencing of the gene was performed. In addition, $\mathrm{dHPLC}$ was applied to the study of the ABCC6 gene in 7 families. The results show that mutant alleles are present mostly in com- pound heterozygous state. The great majority of mutations are located in the carboxy-terminal of the protein and almost all mutations involve aminoacidic residues located in the intracellular site. Several new variants, confirmed as causative mutations by excluding their presence in 100 control alleles, were found. In conclusion, our study confirms the genetic heterogeneity of PXE and underlines the usefulness of combining different techniques for the screening of mutations in the ABCC6 gene in families with PXE.

Financial support from MIUR (2004064073-001), EC 6th Programme CA GENESKIN (512117), and PXEInternational.

\section{Hyaluronan content and gene expression for hyaluronan synthases and hyaluronidases in the umbilical cord of healthy and Down syndrome fetuses}

E. Karousou, M. Viola, D. Vigetti, A. Genasetti, P. Moretto, F. Pallotti, M. Aboudan, M. Rizzi, G. De Luca, A. Passi Dipartimento di Scienze Biomediche Sperimentali e Cliniche, Università dell'Insubria, Varese, Italy

The mechanisms by which the excess genetic material of chromosome 21 results in the dysmorphologic features of Down syndrome (DS) are largely unknown. Since HA plays a central role in many morphogenetic processes during embryogenesis, an alteration in its metabolism could be involved in the pathogenesis of several structural defects of DS. The extracellular matrix of umbilical cord (UC) is the mammalian tissue with one of the highest content of HA. Therefore we sought to explore the quantitative HA modifications during gestation, tissue distribution and HA metabolism in euploid and DS UCs. Quantitative and molecular size analyses were performed using HPLC and FPLC. Tissue distribution was visualized by immunohistochemistry. Gene expression for HA synthases (HAS) and hyaluronidases (HYAL) were quantified by realtime PCR techniques and HYAL activity was detected by zymography. Immunohistochemistry showed a larger amount of Wharton's jelly HA in DS UCs than in euploid UC. Real-time PCR analysis showed a higher expression of HAS 2 and a lower expression of HYAL 2 in the Wharton's jelly of DS fetuses compared to that of euploid fetuses at 14 weeks of gestation. On the contrary, at term HYAL 2 expression was higher in DS specimens. Zymographic studies showed a similar behaviour with a lower HYAL activity at early gestation and a higher HYAL activity at term gestation in DS UCs compared to euploid specimens. We can conclude that HA is more represented in DS UCs than in euploid. A complex alteration of the HA metabolism characterized by an increased synthesis of lower weight HA molecules is a peculiarity of DS UCs.

\section{New insight on the pathogenesis of clinical manifestations in Pseudoxanthoma Elasticum}

I. Pasquali Ronchetti, M.I. Garcia-Fernandez, ${ }^{2}$ F. Boraldi, D. Quaglino, D. Gheduzzi, C. Paolinelli DeVincenzi, R. Tiozzo, ${ }^{1}$ S. Bergamini, D. Ceccarelli, U. Muscatello ${ }^{1}$

Dept. of Biomedical Sciences, ${ }^{1}$ INFM - (S3), University of Modena and Reggio Emilia, Italy; ${ }^{2}$ Dept. of Human Physiology, University of Malaga, Spain

Pseudoxanthoma elasticum (PXE) is a genetic disease inducing calcification and fragmentation of elastic fibers in skin, vessels and eye. It is due to mutations of ABCC6 gene encoding for the membrane transporter MRP6. The physiologial role of MRP6 and the pathogenesis of lesions are unknown. Clinical and histological damages similar to those in 
PXE are present in genetic hemolytic disorders. The hypothesis is that an imbalanced redox status, already observed in hemolytic disorders, may be present in PXE. Dermal fibroblasts from PXE patients have been assayed for ROS, malondialdehyde (MDA), and glutathione (GSH) contents, and for the activities of enzymes involved in the cell redox balance. Mitochondrial activities have been investigated as possible source of oxidant species.

Results. PXE fibroblasts suffer from a vitamin E-sensitive mild chronic oxidative stress due to imbalance between production and degradation of oxidant species. Compared to controls, PXE cells have significantly higher content of ROS and MDA, higher ratio of oxidised to reduced GSH, a higher activity of superoxide dismutase (SOD) and of glutathione transferase (GT). By contrast, catalase (CAT) and glutathione reductase (GR) activities are similar to controls. The significantly higher levels of Mn-SOD and of mitochondrial membrane potential in PXE cells compared to controls indicate mitochondria as source of superoxide anion and of ROS. Therefore, the imbalance between production and degradation of oxidant species in PXE cells may also depend on loss of mitochondrial $\Delta \psi_{\mathrm{m}}$ control with overproduction of $\mathrm{H}_{2} \mathrm{O}_{2}$. Whatever induced, PXE cells suffer from a mild chronic oxidative stress and this can explain the great majority of structural and biochemical alterations already reported in PXE.

Financial support from MIUR (2004064073-001), EC $6^{\text {th }}$ progr. CA GENESKIN (512117), and PXE-Intern.

\section{Contribution of amino acid sulfur to proteoglycan sulfation in a mouse model of diastrophic dysplasia} F. Pecora, ${ }^{1}$ B. Gualeni, ${ }^{1}$ A. Forlino, ${ }^{1}$ A. Superti-Furga, ${ }^{2}$ G. Cetta, ${ }_{1}^{1}$ R. Tenni, ${ }_{1}^{1}$ A. Rossi ${ }^{1}$

${ }^{1}$ Department of Biochemistry, University of Pavia; ${ }^{2}$ Centre for Pediatrics, University of Freiburg, Germany

Sulfate transporter chondrodysplasias are caused by mutations in the diastrophic dysplasia sulfate transporter (DTDST) gene that lead to impaired uptake and intracellular depletion of sulfate with ensuing undersulfation of newly synthesized cartilage proteoglycans (PGs). We have used our mouse model of diastrophic dysplasia to estimate the contribution of cysteinederived sulfur to cartilage PG sulfation. Cartilage fragments from newborn wild-type and mutant animals were double labeled with $\left[{ }^{3} \mathrm{H}\right]$ glucosamine and $\left[{ }^{35} \mathrm{~S}\right]$ cysteine and the ${ }^{35} \mathrm{~S} /{ }^{3} \mathrm{H}$ ratio in glycosaminoglycans was determined; the ${ }^{35} \mathrm{~S} /{ }^{3} \mathrm{H}$ ratio was 4 fold higher in mutant animals compared to the controls. Subsequently, wild-type and mutant animals at 1 day of age were injected with $\left[{ }^{35} \mathrm{~S}\right]$ cysteine and after $24 \mathrm{~h}$, the specific activity $(\mathrm{dpm} / \mathrm{nmol})$ of the 4-sulfated disaccharide was measured in skin and cartilage. In both tissues the specific activity was increased in mutant compared to wild-type littermates. On the basis of these data, newborn mutant and wild-type mice were injected daily with $\mathrm{N}$-acetylcysteine; after $\mathrm{I}$ week cartilage PG sulfation was measured by HPLC disaccharide analysis. In mutant mice a moderate increase in $P G$ sulfation was observed in the animals treated with the drug compared to the ones treated with a placebo. These data confirm that the pathway by which sulfate is recruited from the intracellular oxidation of thiol compounds for PG sulfation is active in cartilage in vivo and suggest potential therapies of diastrophic dysplasia with thiol compounds.

Work supported by Italian MIUR grant no. 2003052778.

\section{Angioprevention: angiogenesis in a chemopreventive setting}

U. Pfeffer, N. Ferrari, R. Venè, G. Fassina, R. Benelli, D.M. Noonan, ${ }^{1}$ A. Albini

National Cancer Research Institute, Genova; ${ }^{1}$ Università degli Studi dell'Insubria, Varese, Italy

Acquisition of an angiogenic potential, the angiogenic switch, is a key step in progression to tumor maligancy. Chemoprevention focuses on cancer prevention using agents devoid of collateral effects. We note that angiogenesis is a common key target of most chemopreventive molecules, a concept termed Angioprevention. We are investigating angioprevention drugs to reveal mechanisms and identify novel candidates. Common mechanisms of action involve inhibition of protease activity or of leukocyte infiltration, whose contribution to cancer through MMP-9 production is documented.

$\mathrm{N}$-acetyl-cysteine (NAC) prevents angiogenesis in the Matrigel sponge assay and reduced growth of xenografts of the highly angiogenic Kaposi's sarcoma in vivo. NAC inhibits MMP-2 and M MP-9 activity via the free sulfhydryl group that mimics the inhibition conferred by the free cysteine in the propeptide, thus is a broad MMP inhibitor. The green tea flavonoid, epigallocatechin-3-gallate (EGCG), linked to reduced tumor incidence by epidemiological evidence, shows strong inhibition of M MP-2 and to a slightly lesser extent M MP-9. The green tea flavonoid EGCG, also represses neutrophil infiltration and neutrophil-mediated inflammation-associated angiogenesis, thus EGCG also indirectly targets MMP-9. EGCG has also been observed to potently inhibit neutrophil elastase as well.

We analyzed the regulation of gene expression they exert in primary human umbilical endothelial cells (HUVEC) in culture with functional genomics. Expression profiles obtained through Affymetrix GeneChip arrays identified overlapping sets of genes regulated by the anti-oxidants and possible mediators potentially representing a fingerprint of the anti-angiogenic switch.

\section{Ectopic decorin induces proteomic and cytoskeleton modulation of breast cancer cells}

I. Pucci Minafra, G. Di Cara, L. Minafra, L. Santoro,

S. Caricato, P. Cancemi, S. Feo, S. Minafra

Università di Palermo, Dipartimento di Oncologia Sperimentale e Applicazioni Cliniche, Centro di Oncobiologia Sperimentale, Dip. Oncologico 'La Maddalena', Palermo, Italy

During the invasive growth neoplastic cells enter in dynamic contact with several components of the extracellular matrix that may influence gene expression and induce phenotypic modulation of neoplastic cells. Among these environmental factors, decorin, a representative member of the small leucinerich proteoglycan family, occupies a central role because of its ability to interact with collagens and cellular receptors and to modulate biological activities. To test the effects of ectopic decorin expression in neoplastic cells we performed a comparative study of decorin-transfected $8701-B C$ clones vs the parental cell line, applying 2D-IPG, western blot and RT-PCR methodologies. Our preliminary results showed that the protein complement expressed by cells following transfection undergoes significant modifications. Protein modulation involves some cytoskeletal proteins, metabolic enzymes and chaperonins. Cell morphology assays show remarkable cell surface modifications of transfected clones. Since cytoskeleton, besides its role in maintaining cell polarity, is also involved in signal transduction, its modification in the transfected clones is probably associated with complex responses induced by ectopic decorin. In addition, transfected clones display a significant 
reduction of the levels of matrix proteases released into the media culture, which correlates with a downregulation of the transcription of the corresponding genes. These results provide additional insights into the reported effect of decorin in neoplastic cell behaviour.

\section{Work supported by MIUR cofin to S.M. 2002.}

\section{Mutations in collagen I affect the binding to small leucine-rich proteoglycans}

R. Tenni, ${ }^{1}$ M. Sonaggere, ${ }^{1}$ M. Viola,${ }^{1}$ M.E. Tira, ${ }^{1}$ A. Forlino, ${ }^{1,2,}$ J.C. Marini ${ }^{2}$

${ }^{1}$ Dept. of Biochemistry, University of Pavia, Italy; ${ }^{2} B E M B$, NICHD, NIH, Bethesda, MD, USA

Mutations in collagen I cause Osteogenesis Imperfecta (OI). We studied the effect of mutations in the $\alpha 2$ (I) chain on the interaction with decorin ( $D C N)$, biglycan (BGN) and fibromodulin ( $F M)$, all small leucine-rich proteoglycans (SLRPs). Collagens were purified from culture media of skin fibroblasts from skin biopsies of three lethal and four non-lethal OI patients. DCN and FM were purified from bovine tendon, recombinant $B G N$ from a clone of stable transfected $\mathrm{CHO}$ cells. The interaction was determined by ELISA using biotinylated SLRPs (1. Tenni et al., Eur J Biochem 269, 1428, 2002). Our results show that mutations affect type I collagen interactions with the three SLRPs, the affinity apparently decreasing as the mutation is more C-terminal. At least for DCN and FM, this can be explained by the presence in collagen of multiple binging sites for these two SLRPS and the fact that collagen Lys/ Hyl are essential for the binding to DCN (see 1.) and FM (unpublished results); in particular, post-translational Hyl overglycosylation in the portion of the triple helix $\mathrm{N}$-terminal with respect to the mutation probably causes steric hindrance for SLRP binding. Superimposed on these findings, we have found a very low binding to $D C N$ and $F M$ and a low binding to $B G N$ by lethal mutations G421D and G622D, both in the binding region for CS/DS sulfate PGs (2. Di Lullo et al., J Biol Chem $277,4223,2002)$. Different affinities for the three SLRPs, in particular a very low binding for $\mathrm{FM}$, were obtained for two more C-terminal mutations (non-lethal G688S and lethal G706S), both in the binding region for KS PGs.

Work supported by University of Pavia and MIUR (PRIN 2003055193 and 2004055533).

\section{Hyaluronan metabolism in human breast cancer cell line 8701BC.}

M. Viola, D. Vigetti, E. Karousou, P. Moretto, A. Genasetti, M. Rizzi, F. Pallotti, G. De Luca, A. Passi

DSBSC Insubria University, Varese, Italy

Qualitative and quantitative changes are frequently observed in the extracellular matrix stroma surrounding cancer. High level of hyaluronan (HA) is often associated with malignant progression in many cancers, such as breast cancer, colorectal cancer, and glioma. ${ }^{1}$ Hyaluronan-rich matrices around tumors favor the cancer cells migration and infiltration of newly formed blood vessels. ${ }^{2}$ Changes in hyaluronan content within primary tumors result from complex interactions between the carcer cells and associated stroma: growth factors and cytokines produced by the carcinoma may stimulate fibroblasts embedded in the stroma to increase the production of hyaluronan and associated hyaluronan-binding matrix components. In a recent paper carcinoma-associated fibroblasts are reported to be responsible for recruiting endothelial cells into tumor thereby boosting tumor angiogenesis. ${ }^{3}$ Human breast cancer cell line $8701 \mathrm{BC}$, expresses the enzymes involved in HA metabolism, the synthases HAS2 and 3 and the hyaluronidases; nevertheless cells do not produce HA in ECM but only few molecules of HA are evident within the cells. In co-culture in Transwell system with fibroblasts and tumor cells it was evident that $8701 \mathrm{BC}$ cells and fibroblasts increased the expression of the HA synthases, demonstrating a cross-talk between these cells; further analysis are in progress to elucidate the molecules involved in this interaction.

\section{References}

1. Itano N, et al.; (2004). J. Biol. Chem., 279, 18679-87. 2. Savani RC et al (2001) J. Biol. Chem., 276, 36770-8. 3. Orimo A et al. (2005), Cell, 6;121(3):335-48.

\section{Microdetermination of chondroitin sulfate in normal and PXE-affected human plasma by HPLC and fluorophore- assisted carbohydrate electrophoresis}

N. Volpi, F. Maccari

Department of Biologia Animale, University of Modena and Reggio Emilia, Modena, Italy

An inexpensive, simple, sensitive and reproducible analytical method for the quantitative and qualitative evaluation of chondroitin sulfate (CS) from human blood plasma samples by using fluorophore-assisted carbohydrate electrophoresis (FACE) has been developed. After treatment with a nonspecific protease to convert proteins into small peptides, CS from $100 \mu \mathrm{l}$ of normal human plasma was extracted by using a filter membrane (molecular mass cut-off of 3,000 Da) or purification by using a anion-exchange resin. The recovered CS was converted into unsaturated disaccharides through the action of chondroitin $A B C$ lyase, derivatized with 2-aminocridone by reductive amination in the presence of cyanoborohydride and separated by FACE. The linearity, sensitivity and reproducibility of the method were determined in comparison with HPLC equipped with postcolumn derivatization and fluorescence detection using 2-cyanoacetamide as a fluorogenic reagent. This method was applied to the characterization of CS in healthy human subjects, PXE-affected and carriers ageing from 13 to 74 years old. 


\section{BIOMATERIALS}

\section{Electromagnetic bioreactor effects on the growth of SAOS-2 cells seeded onto a titanium fiber mesh scaffold} L. Fassina, ${ }^{1}$ G. Mazzini, ${ }^{2}$ V. Maliardi, ${ }^{3}$ E. Saino, ${ }^{4}$ M.G. Cusella, ${ }^{3}$ F. Benazzo, ${ }^{5}$ G. Magenes, ${ }^{1}$ P. Speziale, ${ }^{4}$ L. Visai ${ }^{4}$

${ }^{1}$ Dept. of Informatics and Computer Science, ${ }^{2}$ Institute of Molecular Genetic, Histochemistry and Cytometry Section of CNR, ${ }^{3}$ Dept. of Experimental Medicine, Histology and Embryology Unit, ${ }^{4}$ Dept. of Biochemistry, Medicine Section, ${ }^{5}$ Dept. SMEC, IRCCS San Matteo, University of Pavia, Italy

Several porous biomaterials are used as 3D scaffolds for bone tissue engineering. Moreover, increasing evidence suggests that physical stimuli, such as shear stress and electromagnetic field, can modulate bone histogenesis and calcified matrix production in vitro and in vivo., ${ }^{1,2}$ Our aim was to investigate the effects of an electromagnetic wave on human osteosarcoma SAOS-2 cells in terms of proliferation and calcified matrix production. SAOS-2 cells were seeded onto 3D titanium fiber mesh scaffolds, and electromagnetically stimulated (electromagnetic culture) or not (control culture). Immunofluorescence, Scanning Electron Microscopy (SEM), ELISA and RT-PCR analysis were performed on both scaffolds. Immunofluorescence and SEM analysis revealed that the electromagnetic stimulation improved the cell distribution on the scaffold surface in the electromagnetic culture compared to control culture. Furthermore, the electromagnetic stimulation significantly increased the scaffold coating with calcified matrix, and with bone proteins such as type I collagen, decorin, and osteopontin. RT-PCR analysis showed an up-regulation of the bone matrix protein transcription, suggesting that the electromagnetic stimulation could be used to improve osteoblast growth and calcified matrix development in vitro.

\section{References}

1. Heermeier K, et al. Bioelectromagnetics 1998;19(4):222-31.

2. Aaron RK, et al. Clin Orthop Relat Res 2004 Feb; (419):30-7.

Financial support: PRIN Grant (2004) to L.V. and Fondazione CARIPLO Grant (2004) to F.B.

\section{Heart valve Elastin Leaflet as starting material for} tissue engineering

A. Gandagliaa, ${ }^{1,2}$ M. Spina, ${ }^{2}$ G. Gerosa, ${ }^{2}$ I. Vesely ${ }^{2}$

${ }^{1}$ Childrens Hospital Los Angeles, University of Southern California, USA; ${ }^{2}$ University of Padova, Italy

Objectives: The elastic fiber scaffold is known to play a major role in the biomechanics of heart valve leaflets. It is also known that elastic fibers are not normally turned over in adult valves. The elastin scaffold could thus be used as a novel substrate for a tissue engineered aortic valve. Although the elastin scaffold has been studied mechanically, detailed investigations on its ultrastructure have been lacking. Our objective therefore are to more completely understand heart valve elastic fiber ultrastructure.

Methods: Elastic fiber scaffolds were obtained from pig aortic and pulmonary heart valve leaflets. Initially a detergent based decellularizing procedure was performed, followed by a collagenase (purified on an elastin column) treatment. Third passage smooth muscle cells (SMC), from rat neonatal ascending aorta and human fibroblasts (HF) from skin, were seeded on the scaffold. Decellularized and repopulated scaffolds were examined with transmission and scanning electron microscopy and by immunohistochemistry.

Results: No collagen was observed after treatment with collagenase, in either the aortic or in the pulmonary valve. Elastin microfibrils were not affected by this procedure. Histologic analyses demonstrated the absence of cell nuclei in the digested scaffolds. Preliminary results show that SMC and fibroblast are attached to both aortic and ventricularis surface of the leaflets after one week of culture. Conclusions: SMC and HF seeding on valve elastin scaffolds has the potential to rebuild a viable aortic and pulmonary valve.

\section{Histologic, histomorphometric and ultrastructural evaluation of titanium particles detached from titanium plasma sprayed endosseous dental implants}

E. Orsini, ${ }^{1}$ M. Franchi, ${ }^{1}$ D. Martini, ${ }^{1}$ B. Bacchelli, ${ }^{1}$ A. Trirè, ${ }^{1}$ M. Quaranta, ${ }^{1}$ M. Fini, ${ }^{2}$ A. Ruggeri ${ }^{1}$

${ }^{1}$ Dept. Human Anatomy, University of Bologna; ${ }^{2}$ Laboratory of Experimental Surgery, IOR, Bologna, Italy

The implant surface topography is one of the factors enhancing the osseointegration of endosseous dental implants. Rough implant surfaces favour early adhesion of blood clot and cells to implant, shortening the implant biological fixation, increasing the device area which is in contact with host tissues and favouring implant primary stability and periimplant osteogenesis, but can also improve the detachment of titanium particles that limit the osteoblast activity and the peri-implant osteogenesis (Urban RM et al., 2000). Our previous research (Franchi M. et al., 2004) demonstrated that titanium granules detach from TPS implant surface during the implant insertion, and are still detectable in peri-implant tissues 14 days after surgery.

24 TPS screws were inserted in sheep tibia. The implants were removed 14 and 90 days after insertion. Implants with surrounding peri-implant tissues were analyzed by LM, SEM, EDAX.Ti granules of 3-60 $\mu \mathrm{m}$ were detectable in peri-implant tissues of 14 and 90 days samples. The Ti particles were observed in marrow spaces of peri-implant bone, in medullary canals of tibia, but also englobed in the newly formed bone. Morphometric analysis investigated the number, the distance from the implant surface, the tissue site (medullary space or bone) and the area of the Ti particles observed in peri-implant tissue. The decreasing of the particles number was higher $(66.55 \%)$ than the reduction of their area $(6 \%)$ from 14 to 
90 days after surgery. These data suggest that the small Ti particles detached from the TPS during implant insertion may be degraded or attached by host cells from 14 to 90 days after surgery.

\section{In vitro and in vivo studies of titanium implants surface microtopography}

A. Trirè, ${ }^{1}$ M. Franchi, ${ }^{1}$ D. Martini, ${ }^{1}$ B. Bacchelli, ${ }^{1}$

V. De Pasquale, ${ }^{1}$ E. Orsini, ${ }^{1}$ G. Giavaresi, ${ }^{2}$ S. Guizzardi, ${ }^{3}$

M. Raspanti, ${ }^{4}$ A. Ruggeri ${ }^{1}$

${ }^{1}$ Human Anatomy, ${ }^{2}$ Experimental Surgery, I.O.R; Bologna;

${ }^{3}$ Experimental Medicine- Histology, University of Parma;

${ }^{4}$ Human Morphology, University of Varese, Italy

Titanium implant osteointegration is strictly connected to the extension of the implant surface which comes into direct contact with the host bone tissue. During implant insertion direct contact to bone is limited to the thread surface, whereas the space between threads is filled with the blood clot. It has been shown that the surface in contact with the clot needs to be roughened to speed up osteointegration (Martini D. et al., 2003; Franchi M. et al., 2004).

This study aims to demonstrate that the rough surface which better favours new bone formation is that most closely simulating the natural bone architecture.

Smooth surface titanium plates, plates with surfaces roughened by sandblasting with $\mathrm{Al}_{2} \mathrm{O}_{3}$ and $\mathrm{ZrO}_{2}$ powders and screw implants with the same surfaces were comparatively analyzed at LM, SEM and TEM.

Human osteoblasts were seeded on the different plates and cell proliferation and differentiation were more pronounced on plates with a surface porosity reproducing the natural bone situation. In particular osteoblasts showed more affinity for $\mathrm{U}$-shaped microconcavities similar in size to those of the bone lacunae (Guizzardi S. et al., 2004).

Implants were inserted in sheep femur and tibia. Screws analysis showed a better outcome of those with U-shaped microconcavities in terms of affinity index, bone ingrowth and bone maturation index from the early weeks after surgery.

Our findings show that rough surfaces with U-shaped microconcavities enhance retention of the blood clot and osteoblasts adhesion, affecting both qualitatively and quantitatively implant osteointegration. 


\section{INDEX OF AUTHORS}

Aboudan M. 322

Agostini C. 317

Albanese N. 321

Albini A. 317, 323

Annovi G. 316

Avenoso A. 316, 317

Bacchelli B. 325

Barbieri F. 320

Bartolini B. 316, 320

Bellotti V. 318

Benazzo F. 325

Benelli R. 317, 323

Bergamini S. 322

Bergwitz C. 322

Bonetti A. 317, 321

Boraldi F. 316, 321, 322

Bosisio P. 320

Brunetta E. 317

Calabrese F. 317

Calatroni A. 316, 317

Campo G.M. 316, 317

Campo S 316, 317

Cancemi P. 321, 323

Caricato S. 321, 323

Carraro F. 316

Ceccarelli D. 322

Cetta G. 318, 323

Cianciulli P. 321

Cicione C. 319

Colalto C. 317

Contin M. 317, 321

Corazza A. 318

Croce M.A. 321

Curtoni F. 318

Cusella M.G 325

D'Ascola A. 316, 317

De Biasi S. 320

Dell'Aica I. 317

Della Torre S. 318

De Luca G. 318, 320, 322, 324

De Pasquale V. 317, 325

Di Cara G. 323

Esposito G. 318

Fassina G. 323

Fassina L. 325

Feo S. 323

Ferlazzo A.M. 316, 317

Ferrari N. 323

Fini M. 317, 325
Forlino A. 318, 322, 323, 324

Forni G.L. 321

Franchi M. 317, 325

Gandaglia A. 315, 319, 325

Garbisa S 317

Garcia-Fernandez M.I. 321, 322

Genasetti A. 318, 320, 322, 324

Gerosa G. 325

Gheduzzi D. 322

Giacobazzi E. 322

Giavaresi G. 317, 325

Giorgetti S. 318

Goldstein S.A. 322

Grigolo B. 319

Gronowicz G. 322

Gualeni B. 323

Guidetti R. 322

Guizzardi S. 325

Hascall V.C. 320

Karousou E. 318, 320, 322, 324

Kozloff K.M. 322

Kuznetsova N.V. 322

Lania A. 317

Leikin S. 322

Livi U. 321

Lo Russo G. 317

Lupi A. 318

Maccari F. 324

Magenes G. 325

Maliardi V. 325

Mangione P. 318

Marabeti M.R. 321

Marchini M. 315, 317, 319, 321

Marini J.C. 322, 324

Marini S. 318

Martini D. 325

Mayer U. 316, 317

Mazzetti S. 320

Mazzini G. 325

Merlini G. 318

Minafra L. 323

Minafra S. 321, 323

Moreschini 0.319

Moretto P. 318, 322, 324

Muscatello U. 322

Naso F. 315, 319

Negri R. 319

Noonan D.M. 323

Orsini E. 325 
Ortolani F. 315, 317, 319, 321

Ottani V. 317

Pallotti F. 318, 320, 322, 324

Paolinelli De Vincenzi C. 321, 322

Pasquali Ronchetti I. 316, 321, 322

Passi A. 318, 320, 322, 324

Pecora F. 323

Pfeffer U. 323

Piazza F. 317

Politi L. 319

Pucci Minafra I. 321, 323

Quaglino D. 316, 321, 322

Quaranta M. 317, 325

Raimondi S. 318

Raspanti M. 317, 325

Rebecchi M. 322

Rizzi M. 318, 322, 324

Rogers L. 316

Rossi A. 318, 323

Ruggeri A. 317, 325

Saino E. 325

Santoro L. 323

Sartor L. 317

Scandurra R 319

Scott J.E. 319
Scotto d'Abusco A. 319

Sonaggere M. 320, 324

Sorokin L. 317

Sorrentino F. 321

Speziale P. 325

Spina M. 315, 319, 325

Stoppini M. 318

Superti-Furga A. 323

Tenni R. 318, 320, 323, 324

Tettamanti G. 315

Tiozzo R. 316, 321, 322

Tira M.E. 320, 324

Trirè A. 325

Tursi V. 321

Uveges T.E. 322

Venè R. 323

Vesely I. 325

Vigetti D. 318, 320, 322, 324

Viglino P. 318

Viola M. 318, 320, 322, 324

Visai L. 325

Vitellaro Zuccarello L. 320

Volpi N. 324

Vonder Mark K. 317

Wild S. 316 